\title{
Talin: A Potential Protein Biomarker in Postmortem Investigations
}

Zahra K. Campell ${ }^{1}$; Insu Kwon ${ }^{2}$; Sheree J. Finley ${ }^{1,3}$; Youngil Lee ${ }^{2}$; Gulnaz T. Javan ${ }^{1}$

\begin{abstract}
Affiliations:
${ }^{1}$ Forensic Science Program, Physical Sciences Department, Alabama State University, Montgomery, AL

${ }^{2}$ Department of Exercise Science and Community Health, University of West Florida, Pensacola, FL
\end{abstract}

${ }^{3}$ Ph.D. Program in Microbiology, Department of Biological Sciences, Alabama State University, Montgomery, AL

*Corresponding author:

Gulnaz T. Javan

Email: gjavan@alasu.edu

Phone: +1 334-229-5202

Keywords: Talin, Postmortem interval, Cadaver, Human brain 


\section{Introduction}

Changes in brain biochemistry attributable to death can result in altered concentrations of individual proteins in postmortem brain tissues. A recent study investigated the degradation of thanatophagy proteins and showed that the levels of key proteins involved in postmortem autophagy increased in the brain specimens of actual cadavers from criminal cases. ${ }^{1}$ According to the natural calendar of decomposition, the internal organs of the deceased decay in a particular order depending on the cause of death, beginning with the intestines and culminating with the brain due to the fact that medial sections of the brain cool more slowly than other tissues. ${ }^{2}$

The role of key proteins in cerebral tissues such as those involved in the neuronal cell cytoskeleton (e.g. talin-1, vinculin) and nitrated proteins (e.g. $\alpha$-enolase, cofilin) involved in neurodegenerative diseases have yet to be elucidated in postmortem tissues. Talin-1 is a ubiquitously expressed protein involved in connecting the integrin family of cell adhesion molecules to the actin cytoskeleton of the plasma membrane in antemortem cells. ${ }^{3,4,5}$ These focal adhesions are contingent upon the interface between talin- 1 and vinculin, a membrane cytoskeletal protein. ${ }^{6}$ Talin and vinculin, with half-lives of $18-21 \mathrm{hrs}^{7}$ Differences in turnover rates of vinculin and talin caused by viral transformation and cell density. Calpains play major roles in regulating the proteolytic breakdown postmortem muscle proteins. ${ }^{8}$ Alpha $(\alpha)$-enolase has been characterized as a neurotrophic factor, a heat shock protein, and hypoxic stress protein. It has also been reported that its upregulation plays a role in hypoxia tolerance and tumor progression. ${ }^{9}$ Cofilin is a member of the actin depolymerizing factor (ADF)/cofilin family, which is a group of actin binding proteins which regulate the assembly and disassembly of actin filaments. ${ }^{10,11}$ There are many methods of estimating the postmortem interval (PMI), all of which have varying degrees of accuracy. There is a paucity of studies that correlate the time since death and cytoskeletal and neuronal protein levels. However, a thorough understanding of proteomic degradation in tissues of dead bodies is crucial for the identification of new techniques for criminal investigations.

\section{Materials and Methods}

Cadaver casesAdult cadavers were kept at $1^{\circ} \mathrm{C}$ in the morgue of the Alabama Department of Forensic Sciences Medical Laboratory Montgomery, AL. Brain samples were collected from 18 corpses of various manners of death (homicide, overdose, and suicide). The cohort data reported for each case were the cadaver age at death, 
sex, weight, height, cause of death, and PMI (Table 1). All procedures were in accordance with institutional guidelines and were approved by the Alabama State University Institutional Review Board (IRB) number 2016011.

\section{Tissue collection and homogenization}

The forensic autopsies were carried out in a morgue at $20^{\circ} \mathrm{C}$. Dissection of brain tissues was performed via sterile scalpels, placed in labeled polyethylene bags, and stored at $-80^{\circ} \mathrm{C}$ until the time of analysis. A glass tissue grinder (Fisher Scientific, Pittsburgh, PA) was used to homogenize the cerebral tissues, and the cells were lysed in ice-cold tissue lysis buffer (pH 7.4) containing $50 \mathrm{mM}$ Tris-HCl, $1 \mathrm{mM}$ EDTA, $1 \mathrm{mM}$ EGTA, $1 \%$ Triton X-100 with complete protease inhibitor (Roche Applied Science, Indianapolis, IN), and phosphatase inhibitor (Roche Applied Science, Indianapolis, IN). The tissue homogenates were incubated on ice for 30 min, and then the tissue lysates were collected by centrifugation at $20,000 \mathrm{~g}$ for $20 \mathrm{~min}$.

\section{Immunoblotting}

The proteins in the lysed brain tissue were separated using SDS-PAGE precast gels (Life Technology, Carlsbad, CA) under reducing conditions and transferred to nitrocellulose membrane. The membranes were blocked with $5 \%$ nonfat milk for $90 \mathrm{~min}$ at $21^{\circ} \mathrm{C}$ then incubated overnight with antibodies at $4^{\circ} \mathrm{C}$. The primary antibodies used in the study were vinculin and talin-1 (Abcam, Cambridge, UK) and cofilin and $\alpha$-enolase (Santa Cruz Biotechnology Inc., Santa Cruz, CA). After washing primary antibodies, membranes were incubated with designated secondary antibodies (goat anti-mouse or rabbit HRP conjugated) (Life Technology, Carlsbad, CA). Blots were analyzed with a QuantityOne (Bio-Rad, Hercules, CA) and quantified with LI-COR Image Studio (LI-COR Biosciences, Lincoln, NE. Protein expression was normalized glyceraldehyde 3-phosphate dehydrogenase (GAPDH). Immunoblotting was performed in triplicate.

\section{Statistical analysis}

All values were expressed as means of \pm SEM. Statistical analysis was performed using ANOVA to identify statistical significance between groups by Graph Pad Prism 6. Statistical significance was set at $\mathrm{p}<0.05$.

\section{Results}


Of the 18 cadaver cases, two were excluded due to low protein concentrations $(<0.120 \mathrm{~g})$ as determined by a Molecular Devices Spectra Max M3 spectrophotometer. The remaining 16 cases were binned into three postmortem interval time groups, 0-24 hrs, 24-48 hrs, and 48-72 hrs (Fig 1). The results of densitometry analysis demonstrated PMI-dependent changes in the postmortem cerebral tissues. Talin-1 bands steadily decreased with increasing post mortem interval (Fig. 2). There was a statistically significant diminished levels in talin-1 between the 0-24 hrs and 24-48 hrs, as well as between 0-24 hrs and 48-72 hrs. Vinculin shows consistent expression across all PMIs. Interestingly, $\alpha$-enolase demonstrated the least expression in the first 24 hrs compared to the other proteins. Cofilin-1 showed a decrease in intensities. There were no statistically significant changes observed for vinculin, $\alpha$-enolase, and cofilin.

\section{Discussion}

Death leads to several sequential events after a person dies. For example, the heart stop beating and the lack of oxygen causes hypoxia within the cells. ${ }^{12}$ Hypoxia and ischemia triggers several factors that lead to the degradation of proteins via proteolytic and autolytic enzymez. ${ }^{13}$ Axonal processes of neurons remained immunoreactive. In the current study, western blot analysis showed distinctive degradation patterns in the four selected proteins. A particularly interesting finding from this study was that talin-1 significantly decreased as the PMIs increased. According to Tan et al., (2015), talin-1 is essential for axonal regeneration in an animal model study in dorsal root ganglion (DRG) neuron culture from Sprague-Dawley rats. ${ }^{14}$ Finehout et al., (2006) demonstrated that $\alpha$-enolase levels increase after death in antemortem samples collection by lumbar puncture compared to postmortem samples collected from the ventricular cerebrospinal fluid (CSF). ${ }^{15}$ In the current study, the greater than three-fold increase observed for $\alpha$-enolase within 48 hours confirmed the results of the Finehout et al., (2006) study. Of note, another interesting finding of the current study is that the GAPDH protein, which was used as an internal loading control for immunoblotting analysis, remained strongly detectable even at the longest PMIs up to 72 hours.

\section{Conclusion}

In this study, using brain tissue samples from actual criminal casework, immunoblotting techniques were demonstrated a substantial correlation between protein integrity and PMI. The current confirms that proteins are 
detectable in cadaver brain tissue even up to 72 hrs after death. Remarkably, talin-1 exhibited statistically significant decreases until the longest PMI time (Group 3). In conclusion, this study showed that talin-1 has a statistically significant correlation that provides strong evidence for its potential use as a biomarker to establish precise PMI estimations. Future studies would involve mechanistic animal models (i.e., mice, pig) to investigate PMI-mediated protein degradation to provide new insight into formulating a new forensic method to determine the time of death. 


\section{References}

1. Javan GT, Kwon I, Finley SJ, Lee Y (2016) Progression of thanatophagy in cadaver brain and heart tissues. Biochem Biophys Rep 5(1):152-159.

2. Blair JA, Wang C, Hernandez D, Siedlak SL, Rodgers MS, Achar RK, Fahmy LM, Torres SL, Petersen RB, Zhu X, Casadesus G, Lee H (2016) Individual case analysis of postmortem interval time on brain tissue preservation. PLoS ONE 11(3):e0151615.

3. Debrand E, El Jai Y, Spence L, Bate N, Praekelt U, Pritchard CA, Monkley SJ, Critchley DR (2009).Talin 2 is a large and complex gene encoding multiple transcripts and protein isoforms. FEBS J 276(6): 16101628.

4. Das M, Ithychanda SS, Qin J, Plow EF (2014) Mechanisms of talin-dependent integrin signaling and crosstalk. BBA-Biomembranes 1838(2):579-588.

5. Critchley DR (2009). Biochemical and structural properties of the integrin-associated cytoskeletal protein talin. Ann Rev Biophys 38(1):35-254.

6. Golji J, Lam J, Mofrad MR (2011) Vinculin activation is necessary for complete talin binding. Biophys J 100(2):332-340.

7. Lee, S. W., \& Otto, J. J. (1996). Differences in turnover rates of vinculin and talin caused by viral transformation and cell density. Exp. Cell. Res 227(2), 352-359.

8. Huff-Lonergan, E., \& Lonergan, S. M. (2005). Mechanisms of water-holding capacity of meat: The role of postmortem biochemical and structural changes. Meat Sci 71(1), 194-204.

9. Díaz-Ramos À, Roig-Borrellas A, García-Melero A, López-Alemany R (2012) $\alpha$-Enolase, a multifunctional protein: its role on pathophysiological situations. BioMed Res Int 2012:156795

10. Klejnot M, Gabrielsen M, Cameron J, Mleczak A, Talapatra SK, Kozielski F, Pannifer A, Olson MF (2013) Analysis of the human cofilin 1 structure reveals conformational changes required for actin binding. Acta Crystallogr D 69(9):1780-1788.

11. Bravo-Cordero J J, Magalhaes MA, Eddy R J, Hodgson L, Condeelis J (2013) Functions of cofilin in cell locomotion and invasion. Nat Rev Mol Cell Bio 14(7):405-415.

12. Di Nunno N, Costantinides F, Melato M (1999) Determination of the time of death in a homicide-suicide case using flow cytometry. Am J Forensic Med Pathol 20(3):228-231. 
13. Magni PA, Pérez-Bañón C, Borrini M, Dadour IR (2013) Syritta pipiens (Diptera: Syrphidae), a new species associated with human cadavers. Forensic Sci Int 231(1-3):e19-23. doi: 10.1016/j.forsciint.2013.05.023

14. Tan CL, Kwok JC, Heller JP, Zhao R, Eva R, Fawcett JW (2015) Full length talin stimulates integrin activation and axon regeneration. Mol Cell Neurosci 68(1):1-8.

15. Finehout EJ, Franck Z, Relkin N, Lee, KH (2006) Proteomic analysis of cerebrospinal fluid changes related to postmortem interval. Clin Chem 52(10):1906-1913.

\section{Legends}

Table 1. Demographic information for the cadaver specimens used to study protein levels in postmortem brain tissues.

Figure 1. Samples were binned based on the PMIs in Group 1 (0-24 hrs), Group II (24-48 hrs), and Group III (48-72 hrs).

Figure 2. Talin-1 levels decreased in a PMI-dependent manner in postmortem brain tissues. (A) Western blot analysis of talin-1, vinculin, a-enolase, and cofilin in postmortem brains at various PMI. (B) Quantitation of talin-1/GAPDH, vinculin/GAPDH, a-enolase/GAPDH, and cofilin/GAPDH. 


\section{Acknowledgements}

This work was supported by National Science Foundation (NSF) grant HRD 1401075 and Forensic Sciences Foundation Lucas Research Grant Program. 


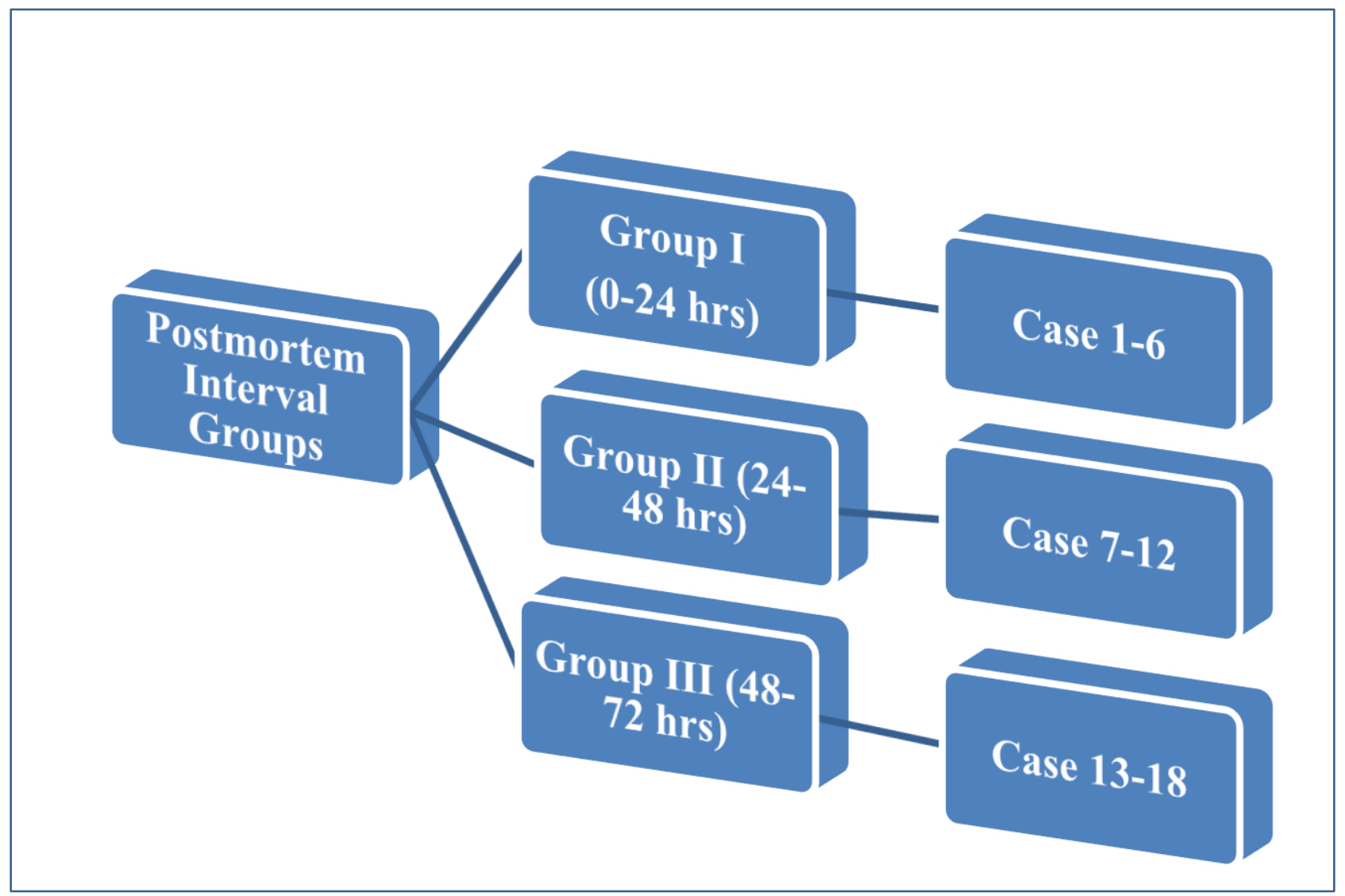

Figure 1. Samples were binned based on the PMIs in Group I (0-24 hrs), Group II (24-48 hrs), and Group III (48-72 hrs). 
A.

\section{Western blotting}

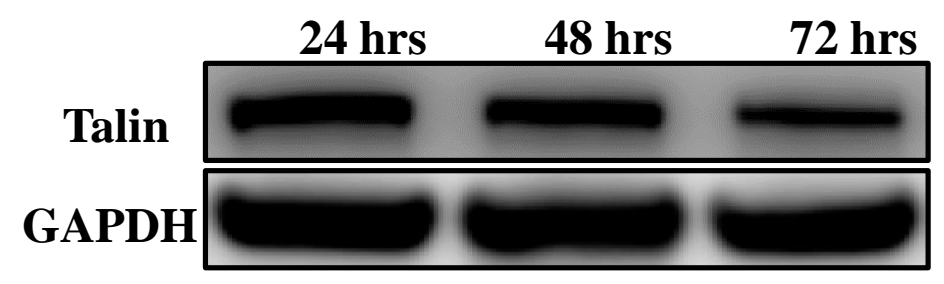

B.

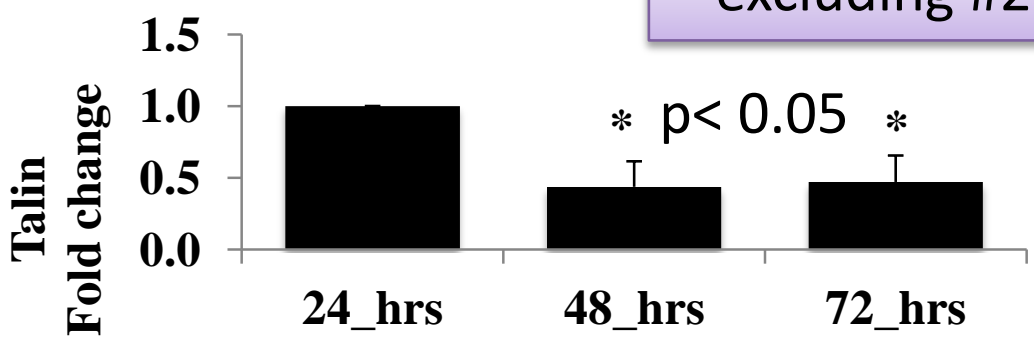

\section{excluding \#2}

\section{:}

2.0

1.5

1.0 0.5 0.0
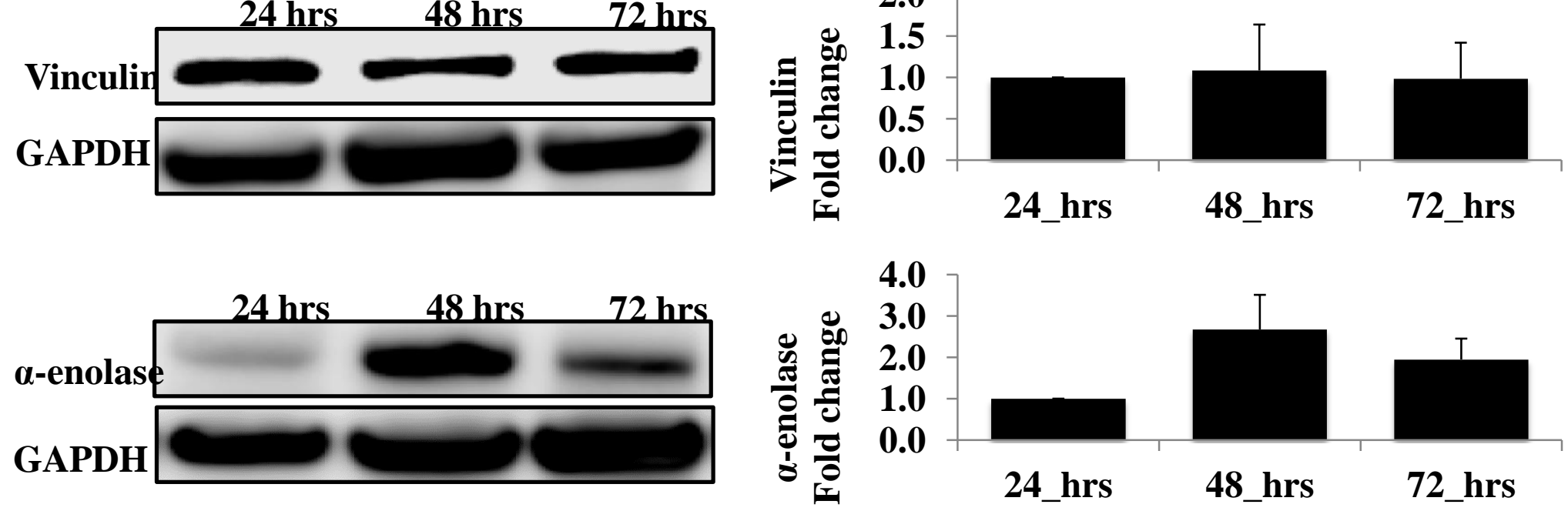

4.0

3.0

2.0

1.0

0.0

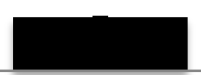

24_hrs
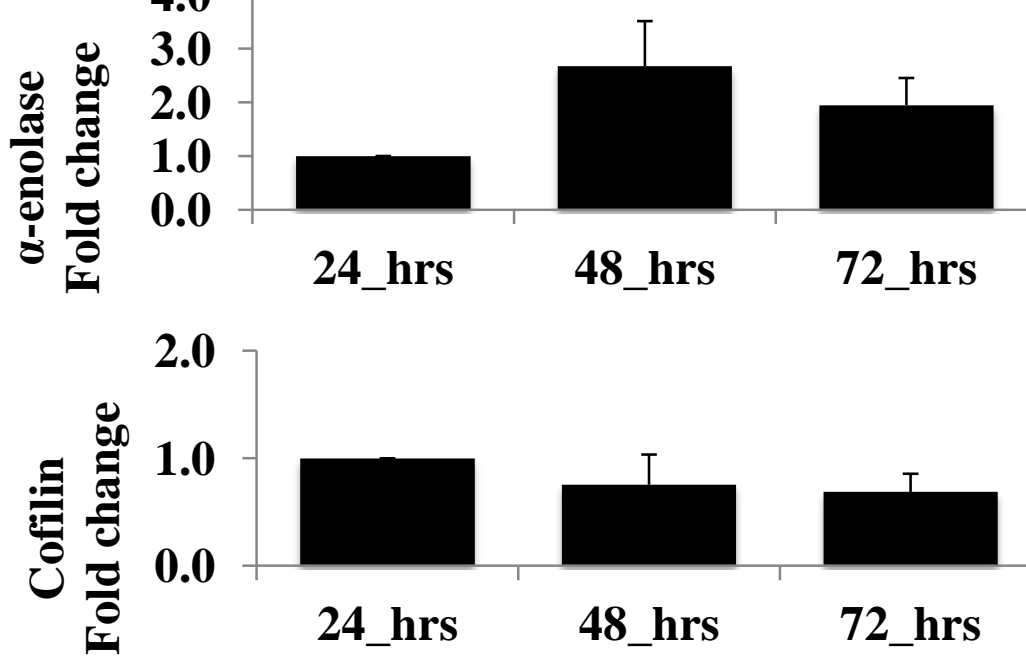

$72 \mathrm{hrs}$

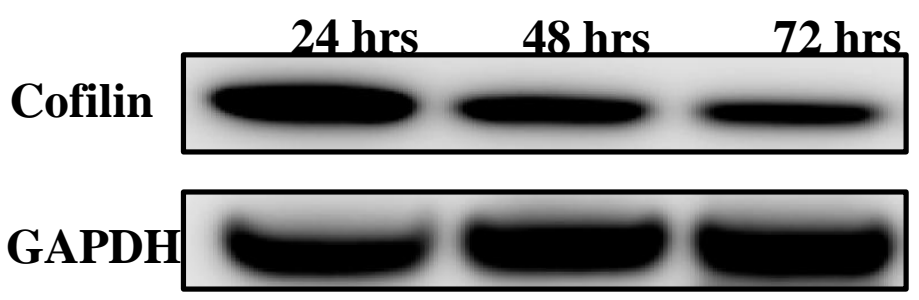

Figure 2. Talin-1 levels decreased in a PMI-dependent manner in postmortem brain tissues. (A) Western blot analysis of talin-1, vinculin, $\alpha$-enolase, and cofilin in postmortem brains at various PMI. (B) Quantitation of talin-1/GAPDH, vinculin/GAPDH, $\alpha$-enolase/GAPDH, and cofilin/GAPDH. 
Table 1. Demographic information for the cadaver specimens used to study protein levels in postmortem brain tissues.

\begin{tabular}{|c|c|c|c|c|c|c|c|}
\hline Case & Age & Sex & Weight (kg) & Height $(\mathrm{cm})$ & Ethnicity & Cause of death & PMI (hrs) \\
\hline 1 & 55 & M & 112 & 198 & $\mathrm{C}$ & Coronary heart disease & 6 \\
\hline 2 & 49 & M & 117 & 188 & $\mathrm{~A}$ & Homicide (GSW) & 16 \\
\hline 3 & 19 & M & 80 & 178 & A & Homicide (GSW) & 17 \\
\hline 4 & 65 & M & 96 & 188 & $\mathrm{C}$ & Suicide (GSW) & 18.5 \\
\hline 5 & 39 & $\mathrm{~F}$ & 119 & 185 & $\mathrm{C}$ & Car accident & 19 \\
\hline 6 & 58 & $\mathrm{~F}$ & 75 & 196 & $\mathrm{C}$ & Overdose & 20 \\
\hline 7 & 50 & $\mathrm{~F}$ & 48 & 170 & $\mathrm{C}$ & Undetermined & 24.5 \\
\hline 8 & 45 & M & 117 & 178 & A & Homicide (Multiple GSW) & 29.5 \\
\hline 9 & 32 & M & 66 & 180 & A & Homicide (GSW) & 32 \\
\hline 10 & 65 & M & 100 & 191 & $\mathrm{C}$ & Coronary Heart Disease & 36.5 \\
\hline 11 & 58 & M & 68 & 173 & $\mathrm{C}$ & Suicide & 47 \\
\hline 12 & 53 & $\mathrm{~F}$ & 62 & 170 & $\mathrm{C}$ & Drowning & 47.5 \\
\hline 13 & 50 & M & 64 & 175 & $\mathrm{C}$ & Homicide (GSW head) & 48 \\
\hline 14 & 48 & $\mathrm{~F}$ & 70 & 160 & $\mathrm{C}$ & Abused & 58 \\
\hline 15 & 67 & M & 59 & 175 & $\mathrm{C}$ & Suicide & 66 \\
\hline 16 & 72 & $\mathrm{~F}$ & 48 & 163 & $\mathrm{C}$ & Blunt Chest Trauma & 68 \\
\hline 17 & 31 & M & 94 & 178 & $\mathrm{C}$ & Suicide & 70 \\
\hline 18 & 47 & $\mathrm{~F}$ & 111 & 168 & A & Stroke & 72 \\
\hline
\end{tabular}

